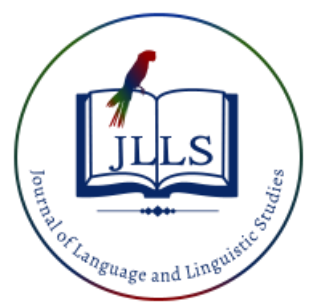

Available online at www.jlls.org

JOURNAL OF LANGUAGE

AND LINGUISTIC STUDIES

ISSN: $1305-578 \mathrm{X}$

Journal of Language and Linguistic Studies, 17(2), 1023-1031; 2021

\title{
Spaced learning: A review on the use of spaced learning in language teaching
}

\section{and learning}

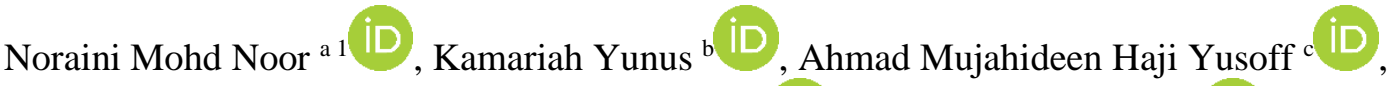 \\ Noormaizatul Akmar Muhammad Nasir ${ }^{\text {d }}$ iD, Nurul Husna Yaacob ${ }^{\text {e }}$ iD \\ ${ }^{a}$ Centre of Academic Service, Sultan Ismail Petra International Islamic College, Peti Surat 68, Nilam Puri, 15730 Kota Bharu, Kelantan \\ Darul Naim. \\ ${ }^{b}$ Faculty of English Studies, University of Sultan Zainal Abidin, Gong Badak Campus, Gong Badak, 21300 Kuala Nerus, Terengganu Darul \\ Iman. \\ ${ }^{c}$ Centre of Foundation Studies, Sultan Ismail Petra International Islamic College, Peti Surat 68, Nilam Puri, 15730 Kota Bharu, Kelantan \\ Darul Naim. \\ ${ }^{d}$ Centre of Academic Service, Sultan Ismail Petra International Islamic College, Peti Surat 68, Nilam Puri, 15730 Kota Bharu, Kelantan \\ Darul Naim. \\ ${ }^{e}$ Centre of Academic Service, Sultan Ismail Petra International Islamic College, Peti Surat 68, Nilam Puri, 15730 Kota Bharu, Kelantan \\ Darul Naim.
}

APA Citation:

Noor, N., Yunus, K., Yusoff, A.M.H, Nasir, N.AM., Yaacob, N.H. (2021). Spaced learning: A review on the use of spaced learning in language teaching and learning. Journal of Language and Linguistic Studies, 17(2), 1023-1031. Doi: 10.52462/j1ls.71

Submission Date: $15 / 02 / 2021$

Acceptance Date:20/05/2021

\begin{abstract}
Time has contributed to most of our daily activities. In the field of understanding how the human brain reacted to specific learning processes, the neuroscientist supports the impact of having multiple learning sessions with the retention of knowledge. Spaced Learning is a product makes out of human's lack of capacity in retaining information and attempts to reduce the forgetting rate. In exploring the condition of how the human mind works and the chances of forgetting, the demonstration of spaced and massed learning in retaining information is recognized in this paper. This paper is aimed to synthesize information on the foundation of Spaced Learning with a focus on language learning, especially to students in academic institutions in Malaysia. This paper used a qualitative design in analyzing documents from articles whereby these articles are synthesized and analyzed using Microsoft excel and the conclusion later on drawn from the analyses. Based on the reviews highlighted in this paper, the practicality of spaced learning is proven in enhancing memory retention in which can contribute to positive performance and can help maximize students' language performance particularly to those who engaged in specific fields of knowledge.
\end{abstract}

Keywords: spaced learning; massed learning; second languages; memory; vocabulary

\section{Introduction}

It is a dream for a teacher in making sure the students get ample information. Within a short period, we try to transmit knowledge in bulk. Have we ever thought that with this massive amount of data that our students need to cope with, can they remember all the pieces and how long does the stored information last? Hence, in this paper, we will unleash the concept of human memory and how it is

\footnotetext{
${ }^{1}$ Corresponding author.

E-mail address: noraini@kias.edu.my
} 
related to language learning. The term "spaced learning" will be the central role of this paper due to the prevailing significance it has for both memory and learning. Spaced learning is a technique in which requires a sufficient number of repetitions, memorization of gained knowledge (Ebbinghaus, 1885). Spaced learning as defined here is the preparation of allocating and revisiting information provided in separate time periods to facilitate the storage of the required information in the long-term memory. In discussing spaced learning, we cannot simply miss its opposite which is "massed learning'. Massed learning is used to portray the preparation of learning information intensively for just one tiny phase without any multiple revisions.

\section{Methodology}

This paper is a reviewed paper based on the exploration of related topics concerning language learning in general and memory strategy in particular. Based on literature dated back from the beginning of conceptualizing the theory of Forgetting Curve by Enbbinghaus (1885) to the recent studies, this paper aimed to synthesize findings from researches upon the application of spaced learning predominantly in language learning. The findings are taken mainly from studies done by researchers in multiple fields whereby these studies applying the algorithm of spaced learning. Spaced learning, which will be discussed further in the next chapter is used to enhance the retention of knowledge in the brain. This paper applies qualitative data analysis in which literature related to the topic has been sorted out using Microsoft excel and further analyzed.

\section{Memory}

Upon discussing the retention of knowledge, we need to highlight the place where memorization occurred. As important as it is, the human brain is one of the greatest creations. Any damage to the brain will affect the human body. There are advertisements regarding the benefit of consuming certain foods or supplements to enhance memory ability. Also, humans challenged the capacity of their brain to the limit in testing the ability of the brain for example in memory competitions. "As humans, we are information-gathering creatures" (Garcia, 2014). Babies, for instance, is like a sponge. From birth to the age of six, the child's brain works in a very diverse way than the adult. At this age, their mind is like a sponge, they tend to mimic and soaking up enormous amounts of data from the environment. According to Ebbinghaus (1885), human memory is divided into three types which are the sensory, short-term, and long-term memory. In learning, for example, we learn through our senses; through vision, hearing, smelling, tasting, and touching. The sensory memory, once triggered which can hold a fairly fixed number of items. Short-term memory, however, is used to attribute to the easy temporary storage of data (Baddeley, 2012). As soon as the information is classified as important, there will be a proceeding revision upon this information and later it will be stored in the long-term memory (Ebbinghaus, 1885).

Baddeley (1974) later on introduces a model known as working memory and uses the term to refer to the technology that not only stores information temporarily but also manipulates it. Working memory works as a system to conduct complex activities for example during the thinking process, learning and comprehension Baddeley, (2002) later proposed multi-component models of working memory in highlighting the relationship between working memory and long-term memory. These components namely the phonological loop, visuospatial sketchpad, and central executive. The first component, the phonological loop composes of a phonological store and the articulatory rehearsal system. Based on this concept, language learners would recall a language item through the presentation of the item according to its phonological elements. However, those elements can only be 
held for a limited duration. In language learning, for example, it is much easier for language learners to recall a one-syllable word compared to a five-syllable word.

The second component is the visuo-spatial sketchpad which is in charge of handling visuo-spatial and kinaesthetic information into a unified representation (Saleem, 2015). When a language learner wants to recall an unfamiliar word, the presentation of words, phonological and written elements of the words play can help in sorting the meaning and also the retention of the words in the memory (Baddeley, 1992). The phonological loop and visuo-spatial are much more independent by themselves while the central executive supervises and integrates information in phonological and visuo-spatial components and it is responsible to direct, organize, update, manipulate and successfully control all information in working memory (Baddeley, 1992).

Now we are moving to the components in our long-term memory. Long-term memory is separated into dissimilar divisions, which are called explicit and implicit memory. Explicit memory is gained consciously through episodic memory or semantic memory. As the name suggests, episodic memory is referred to the remembrance of definite events that have taken place in our lives. Semantic memory, on the other hand, refers to the general knowledge of the world (Baddeley, 1992). Implicit memory is referred to an unconscious or spontaneous memory in which a learner can associate the knowledge with their past experiences or knowledge. Relying on environmental cues and episodic memory, learners use this information as a knowledge assistant. This may be triggered by a particular language classroom or teachers (episodic memory), or depend on whether they already familiar with the form or its usage (semantic memory); or how a learner can produce word forms during a conversation in the target language spontaneously (implicit knowledge) (Garcia, 2014).

The information on various types of memory above can surely be associated with any language learning situation. As a language learner, especially for those who learn a language as their second language would learn the language through a conscious state or in other words, by having a formal and structured condition. Whenever a person sees, hears, or thinks about a concept, an activation in semantic memory will be triggered. This is to say, as we are gaining more knowledge, our memory will be activated even more and resulting in the superior potential of recovering and using the data we have stored in relation to the specified idea. The more opportunities pupils have to study during the teaching and learning process, the more information that may be produced (Cano-c et al., 2017).

Another term related to memory and learning is priming. According to Tipper (1985), priming is a process that involves the presentation of an item in which it influences the processing of a subsequent item. This process will be resulted in making the item be processed easily (positive priming) or more difficult (negative priming). Meaning, if a student experience positive priming, he or she will easily making sense of the next item as related to the previous item (Tipper, 1985). Once a word is primed, the subsequent item related to the word will follow. This condition will eliminate unrelated words and evoke only the related items. There are several types of priming and one of them is repetition priming. This condition occurs during a repeated process between a stimulus and response. Multiple studies have been carried out years back by prominent researchers in the field of psychology and language studies among them are Ebbinghaus (1880), Tomlinson (1932), Collins \& Loftus (1975), and Tipper (1985) show that participants in these studies exhibit a clear advantage of repetition of information in remembering words, pictures and other information.

Teaching vocabularies for instance, as a teacher we may start the lesson by showing few words and encourage the students to engage with activities in maximizing the usage of targetted words. Using the words in sentences is another example of building mental representation for targetted words. During their regular classes, students may learn other subjects while having many opportunities to access the knowledge they have learned previously. By having multiple engagements in a learning activity, 
students will have the ability to reactivate the traces they produced the first time. So, when they revise the topic once again, they will not only clever to start the traces they already have but to use the knowledge they have gained to the new information and for the future lesson as well (Nakata \& Elgort, 2020). Having repetitions do not benefit only in language learning but also in sharpening skills, for example, those who are in working sectors. For example, in a study by Silayo, Migunga, \& Shemwetta (2014), they conclude that having multiple training can lessen the rate of forgetting by the crosscut operators in tree-cutting operations (Silayo et.al, 2014). Consequently, this will eventually lead to their long-term memory.

\section{Spaced vs. Massed learning}

learning has been tested in many different fields in any type of learning that involves a high degree of memorization (Davey, 2014). The most important component in spaced learning is having the spaced practices which are spaced over time. There are alternatives for learners to have their lesson to be spaced. First, a learner needs to revise materials and move to the new information after he or she has successfully remembered the previous lesson. If not, he or she needs to restudy them again while having new information added. Second, a learner could have all the information in bulk and restudy them over time. Researchers claim that although cramming practice right before a test can be an effective strategy but most of us will swiftly forget what we have remembered (Willingham, 2014). Even though this kind of technique seems to be effective and some students performed quite well in their test, less information will be stored in their long-term memory. Short-term memory can store information within 30 seconds shortly after the information is gained. By having a rehearsal, it can maintain a limited amount of information as long as the person wants (Atkinson \& Shiffrin, 1968). Hence, the root of everyone's problem is how to avoid forgetting and can the human mind able to store information for a longer period?

For longer retention, spacing practice is much more effective (Patac, 2013; Gluckman et al., 2014; Silayo et al., 2014; Willingham, 2014; Kang, 2016). The extant literature on the relevance of spaced learning and memory studies mainly relates to Hermann Ebbinghaus (1885), who was the first psychologist to present experimental data on the benefits of spaced learning for memory retention. Ebbinghaus has conducted multiple experiments on himself to investigate how the brain works. Much various research has explored the problem after his contributions and there are various claims made on the benefits of spaced learning.

In Malaysian schools, for example, spaced learning has not gained much popularity. Most of the time, teaching and learning are intended merely to pass a test (Jalaluddin et al., 2011), and it does not serve long-term learning purposes. Spaced learning emphasizes on having retrieval practices across time. Very often in schools, teachers would be teaching subjects to students with less occurrence of previous lessons. Therefore, this will render the opportunity for revisions and finally, the information will slowly fade away (Atikah \& Rezki, 2018). For adult learners, there are criticisms of ditching massed technique as revising strategy. There are claims that learners prefer massed learning because they believe it helps them to memorize better due to the massed revision right before an exam. These students have been crammed for examinations and gotten high scores, so they believe massing information is a useful method. They may have missed out on the need to consider the implications of the strategy for long-term memory and learning. In clarifying this point, I will present some studies from various perspectives, on the advantages of using spaced learning in various fields. These researchers demonstrate the impact of spaced learning on the brain, particularly in terms of knowledge retention, through the use of a variety of studies. 
Analyses found in the literature support that the restoration of information in the brain can be enhanced by having multiple learning gaps (Amiri, 2019; Seibert Hanson \& Brown, 2020; Tabibian et al., 2019). When two or more learning sessions are separated (i.e. spaced apart or distributed) across time, it often produces better learning than cramming to only one single session (Atikah \& Rezki, 2018; Richard C. Atkinson \& Shiffrin, 1968; González Ramírez \& Ramirez, 2015; Mubarak \& Smith, 2008; Sekeres, M. et al. 2016; Toppino \& Gerbier, 2014; Vlach et al., 2019). In one study by Patac (2013), the researcher has examined the effectiveness of using massed and distributed teaching in teaching mathematics. This study involves 37 students in the Surigao City Campus. In both classes, students are given the same teaching strategies but differ in terms of time schedule. The finding has revealed that a distributed teaching program is efficient for average and above-average students only. More advanced learners, on the other hand, prefers learning in massed teaching. This condition may be influenced by the complexity of the subject used. However, for the purpose of remembering mathematical formulas, the use of interleaved or spaced practices can strengthen the association between a problem type and its solution (Kang, 2016).

Teaching science to school children also shown some improvements in students' memory performance after having spaced learning schedules (Gluckman et al., 2014). In their study, On one of three different learning regimens, 36 school-aged youngsters were given lessons regarding food chains (12 students per group): massed, clumped and spaced. From the study, it supports that the participants learning in immediate succession or masses learning gaining a low performance compared to participants in spaced condition. The results from the study reveal that Children in the spaced situation improved much more in memory and generalization skills than those in the massed and clumped schedules (Davey, 2014). Vocabulary learning also gains benefit through the use of spaced repetition. In one study by Amir Reza Lotfolahi and Hadi Salehi (2017), the researchers conducted a study on children learning English as a foreign language. Using an English Time Series as the source of vocabulary knowledge and by having a scheduled learning session (spaced repetition), the study reveals that students in spaced condition outperformed those in massed condition.

Spaced repetition does not limit to only chalk and board because nowadays we have seen a growth rate of online applications such as the Communicative Language Learning (CALL) tool for example in a study by Hudilainen \& Klepikova (2016), the researchers studied the effectiveness of CALL in teaching foreign language vocabulary instruction to 22 cadets enrolled in an EFL class. In another study, by having multiple repetitions on time, the students are showing improvement in vocabulary gains (Hudilainen \& Klepikova, 2016). Learning applications are used as a tool for revising also help students in memorizing. One example of an online language learning application is DUOLINGO. DUOLINGO is a language learning platform that follows the algorithms of spaced repetition. Apart from it, the application is user-friendly and can attract students due to its various online activities and gamification effect (Munday, 2016).

Garcia, (2014) has illustrated in his reviewed paper that the benefits of spaced learning are numerous. The first advantage is that it has a direct influence on brain activity, enhancing memory performance while decreasing neural repetition subdual. Second, it improves the capacity to recall information by activating episodic memory, resulting in higher item recognition and longer information retention in memory. Third, rehearsal facilitates the opportunity for rehearsal in strengthening the nodes or traces which in turn favour the retrieval of information. Lastly, repetition promotes and enhances the ability to acquire knowledge if the students are given adequate spaced practices and feedbacks.

In sum, these studies are proof that Spaced learning has a direct impact on memory, both in terms of recognition and retention, and this may be accomplished through repetition and multiple rehearsals over time. The increased amount of time allows the individual to practice more and this will lead to a 
stronger memory, therefore, facilitate the retrieval of information in the brain. Secondly, The spatial dispersion of events provides for the potential of additional and varied contexts., for example, having spaced practices or tests over time can affect the different traces and later Create a persistent memory containing information that can be retrieved for an extended length of time. Massed learning, on the other hand, would help students especially those who are practicing procrastination and lessen nervousness just before entering the examination hall. The creation of the brain is magical and no learning technique can be granted as the best among all. Different learning preferences and mental capacity of a person affects the selection of learning technique and this paper is aimed in suggesting technique that could help language learners in increasing their memories.

\section{Conclusion}

Relating to the discussion above, utilizing spaced learning in a classroom would be a huge stepping point in improving learning especially in the fields of language acquisition. Teachers may use this technique in teaching due to the profound impacts that it has on memory. Language learners, for example, may use this technique in remembering grammatical formulas or procedures. Teachers would need to arrange their lessons overtimes to maximize students' memorization. Utilizing practices or tests may also act as a supplementary during revision. Researches that have been conducted in Malaysian teaching and learning context are lacking in term of investigating how spaced learning affects the teaching and learning especially in acquiring vocabulary. Hence, future researchers may fill this gap in investigating the benefits of spaced learning techniques to language learners in Malaysian classrooms and to compare how this may affect students' memory retention. This will not be an immediate process, but the teachers must instill awareness about the potential benefits of using spaced learning. Once all parties have seen the potential of using spaced learning in a classroom, proper syllabus amendments should follow. This includes a team of textbook makers and examiners to modify the syllabus again. Spaced learning using a different algorithm for different subjects or learning purposes. The algorithm is calculated to what extend the learner intent to store the knowledge in their memory. A future employee for instance may want to study about his or her future employer just before the interview session. Therefore, he or she may start researching about the company from day one and spaced the information using shorter interleaved practices. As opposed to students, the acquirement of knowledge is hoping to be longer or even forever. Therefore, the spaced have to be multiple and longer between one another. There is no fixed calculation for spaced learning unless for any online application or computer software. Some people would have their own spaced practices as long as they commit themselves to study. It is hoped that Malaysian academic institutions could initiate teaching and learning using the algorithm of spaced learning to encourage students' memorization.

\section{Acknowledgement}

This paper was supported by Sultan Ismail Petra International Islamic College and a grateful thanks goes to the supervisors and fellow lecturers for their insightful reviews and ideas in creating this paper. Much appreciation to the institution for providing financial and facilities in easing the production of this paper.

\section{References}

Amiri, H. (2019). Neural self-training through spaced repetition. NAACL HLT 2019 - 2019 Conference of the North American Chapter of the Association for Computational Linguistics: Human Language Technologies - Proceedings of the Conference, 1, 21-31. https://doi.org/10.18653/v1/n19-1003 
Atikah, D., \& Rezki, A. (2018). Repetition Facilitates Retrieval Opportunity in Vocabulary Learning. IOP Conference Series: Earth and Environmental Science, 175(1). https://doi.org/10.1088/1755$1315 / 175 / 1 / 012148$

Atkinson, R. C., \& Shiffrin, R. M. (1968). Human Memory: A Proposed System and its Control Processes. Psychology of Learning and Motivation - Advances in Research and Theory, 2(C), 89195. https://doi.org/10.1016/S0079-7421(08)60422-3

Atkinson, Richard C., \& Shiffrin, R. M. (1968). Human Memory: A proposed system and its control processes BT - The Psychology of Learning and Motivation. The Psychology of Learning and Motivation, 2(5), 89-195.

Baddeley, A. (1992). Is working memory working? the fifteenth bartlett lecture. The Quarterly Journal of Experimental Psychology Section A, 44(1), 1-31. https://doi.org/10.1080/14640749208401281

Baddeley, A. (2012). Working Memory: Theories, Models, and Controversies. Annual Review of Psychology, 63(1), 1-29. https://doi.org/10.1146/annurev-psych-120710-100422

Cano-c, F., Sarma, S., \& Subirana, B. (2017). Theory of Intelligence with Forgetting : Mathematical Theorems Explaining Human Universal Forgetting using “Forgetting Neural Networks ” Theory of Intelligence with Forgetting: 071.

Chukharev-hudilainen, E., \& Klepikova, T. A. (2016). The effectiveness of computer-based spaced repetition in foreign language vocabulary instruction: a double-blind study. https://doi.org/10.1558/cj.v33i3.26055.Posted

Davey, E. (2014). Spaced Learning applied to teaching biology.

Ebbinghaus, H. (1885). Memory: A Contribution to Experimental Psychology. Annals of Neurosciences, 20(4), 155-156. https://doi.org/10.5214/ans.0972.7531.200408

Garcia, D. . (2014). Spaced Learning: Its Implications in the Language Classroom. 241-258.

Gluckman, M., Vlach, H. A., \& Sandhofer, C. M. (2014). Spacing Simultaneously Promotes Multiple Forms of Learning in Children's Science Curriculum. 273(January), 266-273.

González Ramírez, C., \& Ramirez, C. G. (2015). English for Specific Purposes: Brief History and Definitions. Revista de Lenguas Modernas, 23, 379-386. https://doi.org/10.15517/rlm.v0i23.22359

Jalaluddin, I., Yunus, M., \& Yamat, H. (2011). Improving Malaysian rural learners ' writing skill : A case study. Procedia - Social and Behavioral Sciences, 15, 1845-1851. https://doi.org/10.1016/j.sbspro.2011.04.013

Kang, S. H. K. (2016). Spaced Repetition Promotes Efficient and Effective Learning: Policy Implications for Instruction. https://doi.org/10.1177/2372732215624708

Musa, N. C., Lie, K. Y., \& Azman, H. (2012). Exploring English Language Learning And Teaching In Malaysia. 12(January), 35-51.

Mubarak, R., \& Smith, D. C. (2008). Spacing effect and mnemonic strategies: a theory-based approach to E-Learning. MCCSIS'08 - IADIS Multi-Conference on Computer Science and Information Systems; Proceedings of e-Learning 2008, 2, 269-272.

Munday, P. (2016). The case for using DUOLINGO as part of the language classroom experience Duolingo como parte del curriculum de las clases de. 83-101.

Patac, P. \&. (2013). The Analysis of Two Teaching Programs : Massed and Distributed. 6(March), 5972. 
Saleem, A. (2015). Does memorization without comprehension result in language learning ? By Amjad Saleem Centre for Language and Communication Research School of English, Communication and Philosophy Cardiff University Thesis submitted for the award of Ph.D. Cardiff University J. June.

Seibert Hanson, A. E., \& Brown, C. M. (2020). Enhancing L2 learning through a mobile-assisted spaced-repetition tool: an effective but bitter pill? Computer Assisted Language Learning, 33(1-2), 133-155. https://doi.org/10.1080/09588221.2018.1552975

Sekeres, M. J., Bonasia, K., St-Laurent, M., Pishdadian, S., Winocur, G., Grady, C., \& Moscovitch, M. (2016). Recovering and preventing loss of detailed memory: Differential rates of forgetting for detail types in episodic memory. Learning and Memory, 23(2), 72-82. https://doi.org/10.1101//m.039057.115

Silayo, D. S. A., Migunga, G. A., \& Shemwetta, D. T. K. (2014). Determination of Learning Curves and Forgetting Factors of Two-man Crosscut Saw Operators during Tree Cutting Operations in a 'Learn by Doing ’ Experiment. 4(5), 106-116. https://doi.org/10.5923/j.ajee.20140405.04

Tabibian, B., Upadhyay, U., De, A., Zarezade, A., Schölkopf, B., \& Gomez-Rodriguez, M. (2019). Enhancing human learning via spaced repetition optimization. Proceedings of the National Academy of Sciences of the United States of America, 116(10), 3988-3993. https://doi.org/10.1073/pnas.1815156116

Tipper, P. . (1985). tipper (1985) the negative priming effect. inhibitory priming by ignored objects.pdf (pp. 571-590).

Toppino, T. C., \& Gerbier, E. (2014). About Practice: Repetition, Spacing, and Abstraction. In Psychology of Learning and Motivation (1st ed., Vol. 60). Elsevier Inc. https://doi.org/10.1016/B978-0-12-800090-8.00004-4

Vlach, H. A., Bredemann, C. A., \& Kraft, C. (2019). To mass or space? Young children do not possess adults' incorrect biases about spaced learning. Journal of Experimental Child Psychology, 183, 115-133. https://doi.org/10.1016/j.jecp.2019.02.003

Willingham, D. T. (2014). Strategies That Make Learning Last Four Good Ways to Learn. 1-5.

\section{AUTHOR BIODATA}

Noraini Mohd Noor is a lecturer in the Centre of Academic Services at Sultan Ismail Petra International Islamic College (KIAS) Kelantan, Malaysia. She has been teaching for eight years to different levels of students. Mrs. Noraini received her undergraduate degree from International Islamic University Malaysia (IIUM) specializing in linguistics and a master's degree in Applied Linguistics from University Utara Malaysia (UUM). She published papers in preferred Journals and participated in conferences and forums on English studies.

Assoc. Prof. Dr. Kamariah Yunus is a senior lecturer at the Centre of English Language Studies, Faculty of Languages and Communication (FBK), Universiti Sultan Zainal Abidin (UniSZA). She is currently holding a post as Deputy Dean (Research and Development) at this faculty and has experience teaching linguistic and ESL courses for more than 20 years. She obtained her first degree from the University of El Paso, Texas, USA and earned her Master's degree from the University of Newcastle upon Tyne, UK. She holds a doctoral degree in Corpus Linguistics from the University of Malaya, Kuala Lumpur, Malaysia. Her research interests are corpusbased studies and legal phraseology. Her current research areas are English for Specific Purposes (ESP), Corpus Linguistics, and Discourse Analysis.

Ahmad Mujahideen Bin Haji Yusoff is a Programme Coordinator for Foundation Studies at (KIAS) Kelantan, Malaysia. He served as a lecturer since 2013, teaching subjects related to Islamic Studies namely Quran, Hadith and Usuluddin. He received an undergraduate degree in Usuluddin from University Al-Azhar, a master's degree in Islamic Studies from Universiti Kebangsaan Malaysia (UKM) and a doctoral degree in Contemporary 
Religion from Universiti Malaysia Kelantan (UMK). Most of his writings are related to Tafsir, Hadith and faith. $\mathrm{He}$ is also an editor for local and international journals.

Noormaizatul Akmar Muhamad Nasir currently serves as an English lecturer in the Centre of Academic Services at Sultan Ismail Petra International Islamic College (KIAS) Kelantan, Malaysia. Specializing in English Language Teaching and Malaysian University English Test (MUET), she has 12 years of teaching experience in numerous relevant fields. Noormaizatul Akmar received her first degree from Management and Science University (MSU) majoring in Teaching English as A Second Langauge (TESL) and master's degree in Applied Linguistics from University Utara Malaysia (UUM). She has published papers in various Journals and participated in conferences and forums on English studies.

Nurul Husna Yaacob joins Sultan Ismail Petra International Islamic College (KIAS) Kelantan, Malaysia as an English lecturer in the Centre of Academic Services. Mrs. Husna received her B.A. in English from University Putra Malaysia (UPM) and her M.A in Applied Linguistics from University Utara Malaysia (UUM). Her primary research interests are in the field of second language acquisition and pedagogy. She published papers in preferred Journals and participated in conferences and forums on English studies. 